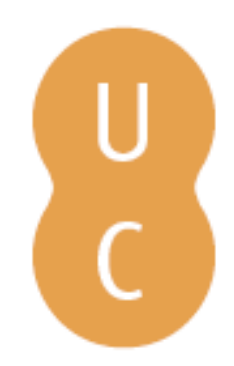

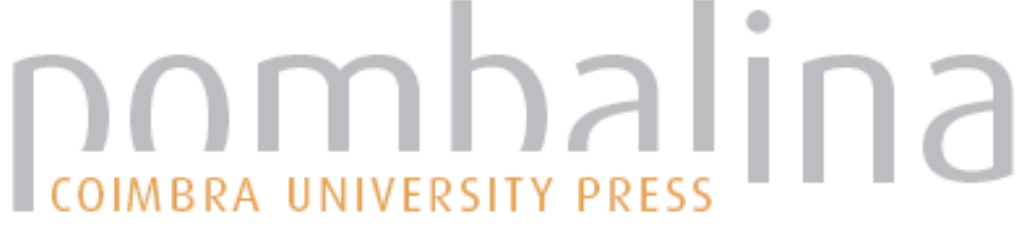

\section{Infeções das vias respiratórias superiores}

Autor(es): Januário, Gustavo

Publicado por: Imprensa da Universidade de Coimbra

URL

persistente: URI:http://hdl.handle.net/10316.2/43119

DOI: $\quad$ DOI:https://doi.org/10.14195/978-989-26-1300-0_18

Accessed : $\quad$ 26-Apr-2023 16:25:07

A navegação consulta e descarregamento dos títulos inseridos nas Bibliotecas Digitais UC Digitalis, UC Pombalina e UC Impactum, pressupõem a aceitação plena e sem reservas dos Termos e Condições de Uso destas Bibliotecas Digitais, disponíveis em https://digitalis.uc.pt/pt-pt/termos.

Conforme exposto nos referidos Termos e Condições de Uso, o descarregamento de títulos de acesso restrito requer uma licença válida de autorização devendo o utilizador aceder ao(s) documento(s) a partir de um endereço de IP da instituição detentora da supramencionada licença.

Ao utilizador é apenas permitido o descarregamento para uso pessoal, pelo que o emprego do(s) título(s) descarregado(s) para outro fim, designadamente comercial, carece de autorização do respetivo autor ou editor da obra.

Na medida em que todas as obras da UC Digitalis se encontram protegidas pelo Código do Direito de Autor e Direitos Conexos e demais legislação aplicável, toda a cópia, parcial ou total, deste documento, nos casos em que é legalmente admitida, deverá conter ou fazer-se acompanhar por este aviso.

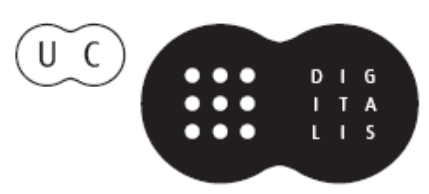


Capítulo 18.

Infeções das vias respiratórias superiores
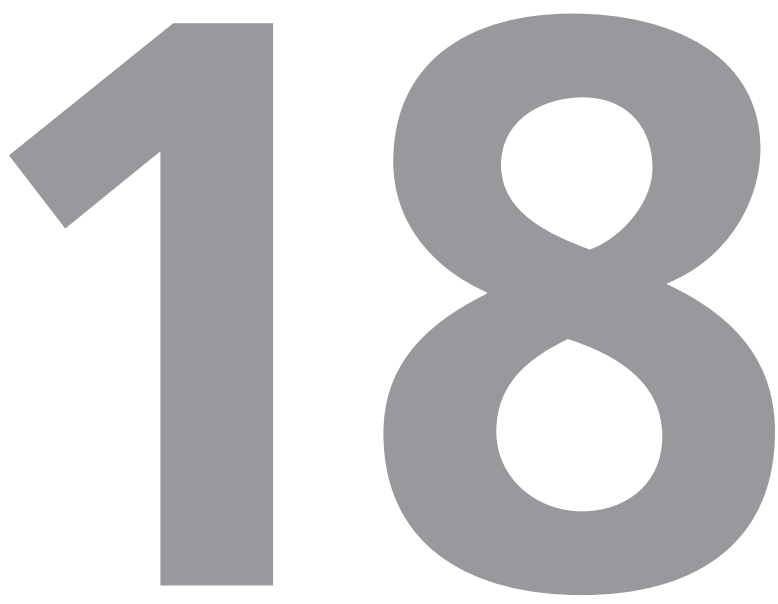

\section{Gustavo Januário}




\subsection{CONTEXTO}

As infeções das vias respiratórias superiores (IVRS) definem-se como doenças infeciosas que anatomicamente se restringem ao aparelho respiratório superior incluindo as fossas nasais, os seios perinasais, o ouvido, a faringe e a laringe. As IVRS mais frequentes e por esse facto abordadas nesta lição, são a nasofaringite aguda (NFA), a otite média aguda (OMA), a rinossinusite bacteriana aguda (RSA), a amigdalite aguda (AA), a laringotraqueíte aguda (LTA) e a epiglotite.

As IVRS são o motivo mais frequente de prescrição de antimicrobianos (ABs). Nos Estados Unidos da América, mais de uma em cada cinco consultas no ambulatório resulta na prescrição de $A B s$, sendo que dez milhões de prescrições de ABs por ano são especificamente para IVRS.
Um dos factos constatados é a prescrição de ABs de largo espetro quando não está indicado nenhum, ou quando em raras circunstâncias podem ser justificadas alternativas de espetro mais dirigido. Por outro lado, a sobreprescrição de $A B s$ está intrinsecamente ligada ao aumento das resistências bacterianas e igualmente à sua disseminação.

Na Europa e em Portugal, 90\% da prescrição de ABs surge no ambulatório. O European Centre for Disease Prevention and Control (ECDC), através da rede de vigilância do consumo de antimicrobianos, publicou dados de consumo de $A B s$ na comunidade referentes a 2010, reportados pelos 24 estados membros e pela Islândia e Noruega (figura 1). O consumo médio foi de 18.3 doses diárias definidas por 1000 habitantes e por dia. Portugal encontra-se

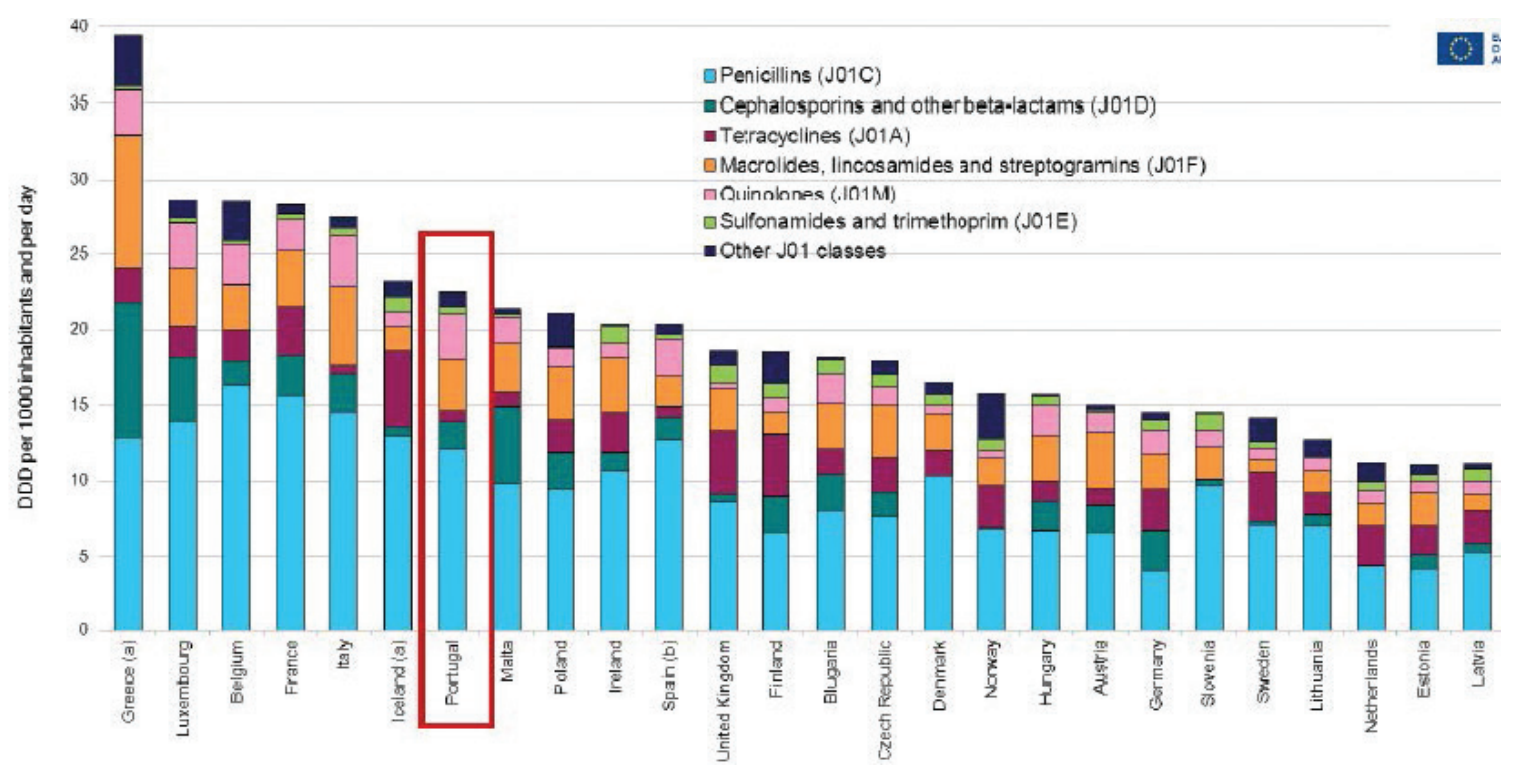

Figura 1. Consumo Europeu de antimicrobianos em 2010. Adaptado de European Centre for Disease Prevention and Control. Surveillance of antimicrobial consumption in Europe, 2010. Stockholm: ECDC, 2013. 
no sétimo lugar entre os países mais prescritores (acima da média europeia) e é especificamente nomeado no relatório como um dos países em que é mais baixa a prescrição e consumo de penicilinas de espectro estreito e em que é mais elevada a prescrição de quinolonas em relação ao consumo total de ABs.

A prescrição racional de ABs é hoje fundamental e é uma prioridade de saúde pública e da segurança dos doentes, incluindo não apenas a diminuição da sobre utilização mas também a prescrição dos agentes adequados. O desenvolvimento de novos ABs para o tratamento de infeções resistentes está praticamente inativo. A decisão clínica de prescrever ou não $A B s$ a uma criança com sintomas de infeção respiratória alta é prática diária para os médicos e é um desafio, na medida em que nalguns casos é difícil distinguir a etiologia viral da bacteriana. O enfâse deve assim estar no uso de critérios clínicos validados quando se faz o diagnóstico de OMA, RSA, AA bacteriana, tal qual estabelecido por protocolos e normas de orientação.

\subsection{DESCRIÇÃO DO TEMA}

\subsubsection{Nasofaringite Aguda}

A NFA sinónimo de vulgar constipação, é uma infeção viral, autolimitada, das VRS que se caracteriza, em grau variável, por congestão nasal, rinorreia, odinofagia, tosse e febre. São vários os vírus respiratórios capazes de a causar, nomeadamente rinovírus, vírus sincicial respiratório (VSR), adenovírus, vírus influenza e vírus parainfluenza, coronavírus, metapneumovírus e bocavírus.

Estima-se que a NFA seja responsável por cerca de $70 \%$ dos motivos de consulta nos serviços de urgência, com picos epidémicos típicos nos meses de inverno, sendo que a frequência dos episódios varia com a idade e grau de exposição a infantários (uma criança "saudável" entre os seis meses e os seis anos, sofrerá entre um a dez episódios de NFA por ano). A taxa de sobre infecção bacteriana da NFA é inferior a $2 \%$. A NFA não complicada tem um perfil evolutivo tipíco que se caracteriza pela existência de sintomas respiratórios (rinorreia e congestão/obstrução nasal, tosse, ou ambos). A rinorreia inicia-se clara e aquosa alterando-se frequentemente no curso da doença, tornando-se mais espessa e mucoide, podendo tornar-se purulenta por vários dias. De seguida a situação reverte e a rinorreia torna-se novamente mucoide, clareia e regride. Estas alterações acontecem independentemente da utilização de ABs. A febre, quando presente na NFA, tende a ocorrer precocemente na doença, desaparece nas primeiras 48 horas de doença e os sintomas respiratórios tornam-se então predominantes. A duração da doença é tipicamente de cinco a sete dias e os sintomas respiratórios atingem por regra o seu pico de gravidade entre o terceiro e o sexto dias e depois melhoram, embora posssam persistir para além de dez dias.

O diagnóstico de NFA é clínico não sendo necessário recorrer a exames complementares. O aspirado da nasofaringe (NF) para testes rápidos de deteção de antigénios virais, cultura, ou técnicas de biologia molecular como a polimerase chain reaction (PCR) para identificação de vírus ou 
bactérias, são utilizados apenas em contexto de investigação. Por outro lado, o valor diagnóstico da identificação de bactérias nas secreções da NF é limitado dada a alta taxa de colonização bacteriana em indivíduos assintomáticos. Perante um

\section{diagnóstico de NFA, não há indicação para tratamento com ABs.}

\subsubsection{Otite média aguda}

A OMA é uma das principais causas de infeção bacteriana na criança. Estima-se que nos três primeiros anos de vida 80 a $90 \%$ apresente pelo menos um episódio de OMA enquanto um terço apresenta dois ou mais. A OMA é um dos principais motivos de observação da criança doente e de prescrição de ABs em idade pediátrica. Tem um impacto social, familiar e económico considerável. Em Portugal, foi publicada a Norma de orientação clínica (NOC) do diagnóstico e tratamento da OMA em idade pediátrica, que subscrevemos nesta lição.

O diagnóstico de OMA baseia-se sempre na conjugação de sinais e sintomas e dos achados da otoscopia, sendo necessário a presença dos seguintes critérios:

1) Membrana timpânica com abaulamento moderado a grave ou presença de otorreia de início recente e não devida a otite externa.

\section{OU}

2) Membrana timpânica com abaulamento ligeiro e início recente de otalgia (que poderá manifestar-se por irritabilidade no lactente) ou eritema intenso da membrana timpânica.

A irritabilidade, recusa alimentar e a febre não são sinais específicos de OMA e podem surgir no contexto de IVRS, sendo fundamental o diagnóstico rigoroso de OMA para evitar o uso inadequado de $A B s$ e as suas potenciais consequências. Alguns fatores de risco identificados para OMA são a idade (pico de diagnóstico entre os seis e os 18 meses), a história familiar de OMA, sexo masculino, frequência de infantário, ausência de aleitamento materno, exposição ao fumo de tabaco e o uso de chupeta.

A fisiopatologia da OMA caracteriza-se pela inflamação e consequente disfunção da trompa de Eustáquio, secundária a uma IVRS, que resulta numa pressão negativa no ouvido médio (OM) com migração de secreções infetadas das VRS e da NF culminando na típica OMA.

Os agentes etiológicos bacterianos mais frequentes são o Streptococcus pneumoniae (25 a 50\%), o Haemophilus influenzae não tipável (15 a 30\%), Moraxella catarrhalis (três a 20\%). Bactérias menos frequentemente envolvidas são o Streptococcus do grupo A (dois a dez por cento), Staphylococcus aureus (um a três por cento), bacilos gram negativos, Pseudomonas aeruginosa e anaeróbios. A vacina conjugada contra o Streptococcus pneumoniae reduziu a incidência de OMA por esta bactéria e alterou os serótipos responsáveis, sendo agora os não vacinais os mais frequentes. As infeções víricas também estão frequentemente associadas a OMA, sendo os vírus mais frequentes o vírus sincicial respiratório, o 
rinovírus, o coronavírus, os vírus parainfluenza e influenza e o adenovírus.

O tratamento da OMA consiste sempre e em primeiro lugar no controlo da dor, utilizando para tal analgésicos como o paracetamol, ou anti-inflamatórios não esteróides como o ibuprofeno. Várias meta-análises sugerem que a maioria das crianças com OMA melhora espontaneamente sem $A B s$, sendo modestos os benefícios da sua utilização. Esta abordagem terapêutica tem aliás sido utilizada em vários países nos últimos anos. O atraso na prescrição de $A B s$, no grupo selecionado para tal atitude, não agravou a recuperação da OMA, nem contribuiu para o aumento de complicações. Sempre que é decidida uma atitude inicial de observação, é necessário assegurar a possibilidade de reavaliação clínica entre as 48 e as 72 horas se não houver melhoria ou se surgir agravamento. Em alternativa pode ser efetuada a denominada prescrição condicionada (os cuidadores levam a receita do $A B$ para o domicílio e iniciam o tratamento dentro de 48 a 72 horas se houver persistência ou agravamento dos sintomas), atitude que implica a compreensão e aceitação por parte dos cuidadores. Esta modalidade demonstrou ser bem aceite pelos cuidadores e levou à redução da utilização de ABs.

A NOC portuguesa emitida pela DireçãoGeral da Saúde recomenda a prescrição imediata de $A B s$ a lactentes com idade inferior a seis meses e a crianças com idade superior que apresentem: OMA com quadro clínico grave, OMA bilateral (se idade inferior a dois anos), otorreia, OMA recorrente (três ou mais episódios em seis meses ou quatro ou mais episódios no último ano), persistência dos sintomas às 48 a 72 horas ou agravamento dos mesmos. O antibiótico de primeira linha recomendado para o tratamento de OMA é a amoxicilina em dose alta $(90 \mathrm{mg} / \mathrm{kg} /$ dia de 12 em 12 horas por via oral) devido à sua eficácia, segurança, baixo custo e ao facto da maioria das bactérias causadoras de OMA serem susceptíveis a este $A B$. No caso de persistência dos sintomas às 48 ou 72 horas após o início do $A B$, a prescrição deverá ser alterada, no caso de OMA não complicada, para amoxicilina com clavulanato, cefuroxime ou ceftriaxona (se falência das opções prévias ou impossibilidade de utilização da via oral). No caso de OMA complicada (OMA que evolui com mastoidite, labirintite, petrosite ou complicações intracranianas) a criança deverá ser referenciada a um serviço de pediatria com otorrinolaringologia. A amoxicilina com clavulanato poderá ainda ser utilizada como $A B$ inicial se tiver sido realizado tratamento nos 30 dias prévios com amoxicilina ou se houver suspeita de infeção por Staphylococcus aureus. A duração do tratamento preconizado na OMA é de sete dias se a idade for inferior a dois anos, no caso de OMA recorrente e se houver falência do tratamento inicial (exceto se o $A B$ prescrito for ceftriaxona que apenas deverá ser administrado durante três dias). Já nas crianças com idade superior a dois anos e na ausência das situações acima referidas, a duração do tratamento é apenas de cinco dias (quadro 1).

O tratamento expectante (observação sem tratamento imediato com $A B$ ) reserva-se a crianças com idade igual ou superior a seis meses e sem quadro clínico grave, devendo estar assegurada a possibilidade de reavaliação médica em 48 a 72 horas, ou antes se necessário, sempre que 


\begin{tabular}{|c|c|c|c|c|c|}
\hline & Antibiótico & Via & Dose & No tomas & Duração \\
\hline $1^{a}$ linha & Amoxicilina & oral & $\begin{array}{c}80-90 \mathrm{mg} / \mathrm{kg} / \mathrm{dia} \\
\text { (máx } 3 \mathrm{~g} / \mathrm{dia} \text { ) }\end{array}$ & $12 / 12 \mathrm{~h}$ & \multirow{10}{*}{$\begin{array}{l}\quad 7 \text { dias se: } \\
\text { - Idade <2 anos } \\
\text { - OMA recorrente } \\
\text { - Falência do tratamento } \\
\text { inicial }\end{array}$} \\
\hline \multirow{4}{*}{$2^{\mathbf{a}}$ linha } & $\begin{array}{c}\text { Amoxicilina + } \\
\text { ác. clavulânico } \\
\text { (formulação } 14: 1 \text { ) }\end{array}$ & oral/i.v. & $\begin{array}{c}80-90 \mathrm{mg} / \mathrm{kg} / \mathrm{dia} \\
\text { (de amoxicilina) } \\
\text { (máx } 3 \mathrm{~g} / \text { dia) }\end{array}$ & $12 / 12 \mathrm{~h}$ & \\
\hline & \multirow{2}{*}{ Cefuroxima } & oral & $\begin{array}{l}30 \text { mg/kg/dia } \\
\text { (máx } 1 \mathrm{~g} / \mathrm{dia} \text { ) }\end{array}$ & $12 / 12 \mathrm{~h}$ & \\
\hline & & i.v. & $\begin{array}{l}80-100 \mathrm{mg} / \mathrm{kg} / \mathrm{dia} \\
\text { (máx } 6 \mathrm{~g} / \mathrm{dia} \text { ) }\end{array}$ & $8 / 8 \mathrm{~h}$ & \\
\hline & Ceftriaxona & i.v./i.m. & $\begin{array}{l}50 \mathrm{mg} / \mathrm{kg} / \mathrm{dia} \\
\text { (máx } 4 \mathrm{~g} / \mathrm{dia} \text { ) }\end{array}$ & $24 / 24 h$ & \\
\hline \multirow{3}{*}{$\begin{array}{c}\text { Alergia à } \\
\text { penicilina } \\
\text { tipo } 1\end{array}$} & Claritromicina & oral & $\begin{array}{l}15 \mathrm{mg} / \mathrm{kg} / \mathrm{dia} \\
\text { (máx } 1 \mathrm{~g} / \mathrm{dia} \text { ) }\end{array}$ & $12 / 12 \mathrm{~h}$ & \\
\hline & Eritromicina & oral & $\begin{array}{l}50 \mathrm{mg} / \mathrm{kg} / \mathrm{dia} \\
\text { (máx } 2 \mathrm{~g} / \mathrm{dia} \text { ) }\end{array}$ & $6 / 6 \mathrm{~h}$ ou $8 / 8 \mathrm{~h}$ & \\
\hline & Azitromicina ${ }^{8 * 8 *}$ & oral & $\begin{array}{c}10 \mathrm{mg} / \mathrm{kg} / \mathrm{dia} \\
\text { (máx } 500 \mathrm{mg} / \mathrm{dia} \text { ) }\end{array}$ & $24 / 24 h$ & \\
\hline \multirow{2}{*}{$\begin{array}{l}\text { Alergia à } \\
\text { penicilina } \\
\text { não tipo } 1\end{array}$} & \multirow{2}{*}{ Cefuroxima } & oral & $\begin{array}{l}30 \text { mg } / \mathrm{kg} / \mathrm{dia} \\
\text { (máx } 1 \mathrm{~g} / \mathrm{dia} \text { ) }\end{array}$ & $12 / 12 \mathrm{~h}$ & \\
\hline & & i.v. & $\begin{array}{l}\text { 80-100 mg/kg/dia } \\
\text { (máx } 6 \text { g/dia) }\end{array}$ & $8 / 8 \mathrm{~h}$ & \\
\hline
\end{tabular}

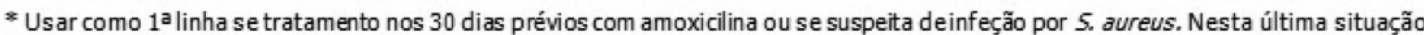
preferir as outras formulações de amoxicilina + ácido clavulânico.

** Tratamento durante 1 ou 3 dias. Recomendada duração de 3 dias se administrado por falência do tratamento antibiótico inicial.

**** Tratamento durante 3 dias.

I.V - endovenoso; i.m - intramuscular; OMA - otite média aguda.

Quadro 1. Antimicrobianos utilizados no tratamento da otite média aguda. Adaptado de Diagnóstico e Tratamento da Otite Média Aguda na Idade Pediátrica. Norma da Direção Geral da Saúde, 2012.

se verifique a persistência ou agravamento dos sintomas (figura 2).

\subsubsection{Rinosinusite bacteriana aguda}

A RSA define-se como uma infeção bacteriana dos seios perinasais, sendo considerada uma complicação de IVRS/NFA ou de inflamação alérgica. O diagnóstico de RSA é clínico e deve ser considerado quando uma criança com IVRS se apresenta com:

i) doença persistente: rinorreia ou tosse diurna ou ambas com duração superior a dez dias, sem melhoria.
OU

ii) Agravamento do curso habitual: agravamento ou re-início de rinorreia, tosse diurna ou febre, após melhoria inicial.

\section{OU}

iii) início grave: febre de valor superior ou igual a $39^{\circ} \mathrm{C}$ e rinorreia purulenta pelo menos durante três dias consecutivos.

É importante relembrar que seis a sete por cento das crianças com sintomas respiratórios têm doença consistente com esta definição pelo que o diagnóstico de RSA exige seguir critérios 


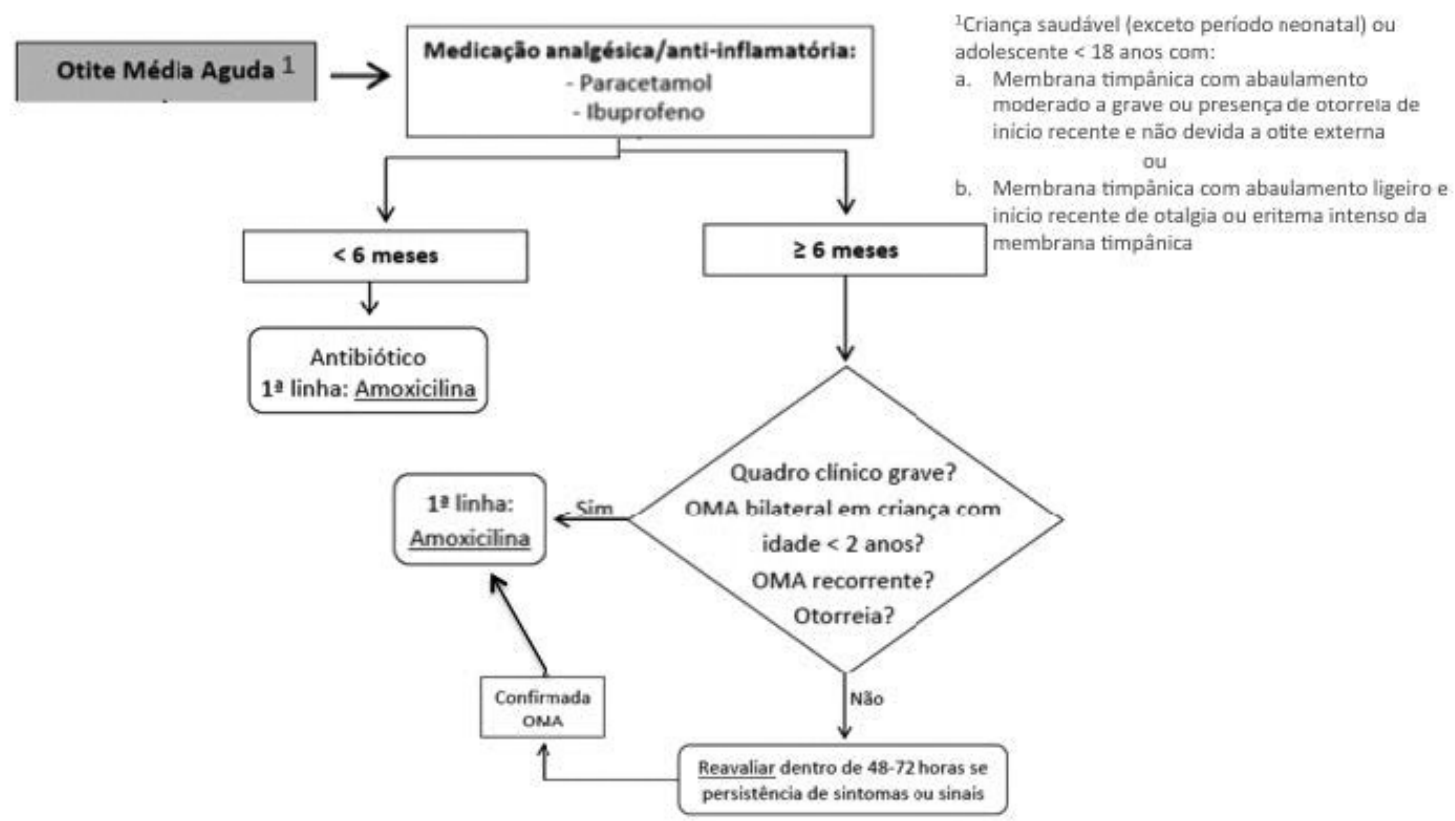

'Amoxiclilina + ácido clavulánico; cefuroxime-axetili; ceftriaxona

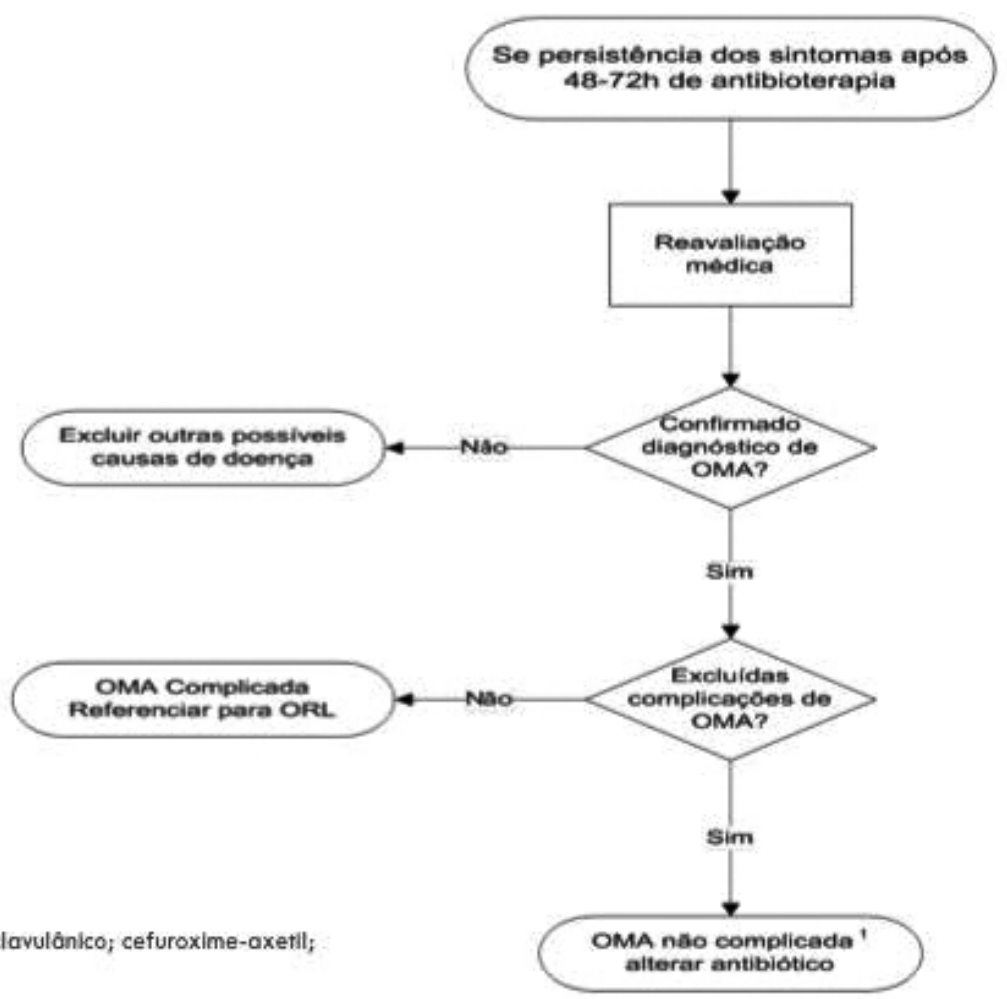

Figura 2. Algoritmo de atuação na OMA. Adaptado de Diagnóstico e Tratamento da Otite Média Aguda na Idade Pediátrica. Norma da Direção- Geral da Saúde, 2012. OMA - otite média aguda; ORL - otorrinolaringologia. 
clínicos estritos que descrevem sinais e sintomas e padrões temporais de uma IVRS, sendo fundamental diferenciar RSA com sintomas persistentes de episódios sequenciais de NFA, estabelecendo claramente a ausência de melhoria dos sintomas. Por outro lado o exame objetivo na RSA é muitas vezes inespecífico e pouco informativo e os exames imagiológicos não distinguem IVRS de RSA pelo que não devem ser requisitados.

A fisiopatologia da RSA caracteriza-se por inflamação e edema da mucosa do óstio do seio promovida por uma IVRS, e numa sequência de eventos que envolve a diminuição da drenagem de secreções por disfunção ciliar, a existência de uma pressão negativa ao nível dos seios perinasais que favorece a aspiração de muco e de bactérias da NF e que finalmente culmina na obstrução funcional e mecânica dos óstios e subsequente multiplicação bacteriana que caracterizam a RSA.

A etiologia microbiológica da RSA foi estabelecida há cerca de 30 anos por estudos que se apoiavam na aspiração direta do seio maxilar em crianças com sinais e sintomas compatíveis com RSA. As bactérias mais frequentemente isoladas na época foram o Streptococcus pneumoniae (30\% dos casos) e o Haemophilus influenzae e a Moraxella catarrhalis (20\% cada) sendo que 25 a $30 \%$ dos aspirados foram estéreis. Apesar de algumas autoridades recomendarem a obtenção de culturas do meato médio, na tentativa de determinar a etiologia da infeção do seio maxilar, não existe qualquer dado comparativo entre tais culturas e as culturas do seio maxilar. Pelo contrário, existem dados que indicam que o meato médio de crianças saudáveis está frequentemente colonizado por Streptococcus pneumoniae,
Haemophilus influenza e Moraxella catarrhalis. O Staphylococcus aureus é raramente isolado nos aspirados em crianças com RSA mas, por razões desconhecidas, é um patogéneo significativo nas complicações orbitárias e intracranianas da RSA. Com exceção da sinusite aguda maxilar associada a infeções de origem dentária, os germens anaérobios respiratórios também são causa rara de RSA. A comercialização e a utilização global de vacinas conjugadas contra o Streptococcus pneumoniae e Haemophilus influenzae alterou substancialmente a taxa relativa destas bactérias sendo atualmente as etiologias principais da RSA os serótipos não vacinais de Streptococcus pneumoniae e Haemophilus influenza não tipáveis.

Recomenda-se tratamento da RSA com ABs, reservando a hipótese de observação adicional durante três dias apenas para a RSA persistente. As crianças que apresentam um início grave de RSA têm presumivelmente uma infeção bacteriana porque febre de valor superior a $39^{\circ} \mathrm{C}$ e que coexiste com pelo menos três dias consecutivos de rinorreia purulenta, não é consistente com o padrão bem documentado de NFA. De forma similar, as crianças com curso agravado de RSA têm uma evolução clínica que não é consistente com a melhoria progressiva da NFA não-complicada (quadro 2).

O tratamento $A B$ da RSA de primeira linha consiste na amoxicilina em alta dose (80 a 90 $\mathrm{mg} / \mathrm{Kg} / \mathrm{dia}$, de 12 em 12 horas, por via oral) durante dez a 14 dias ou pelo menos durante sete dias após controlo dos sintomas. A amoxicilina com clavulanato (formulação 14:1 e com a posologia de amoxicilina já referida) é o $A B$ de segunda linha (primeira linha segundo alguns 


\begin{tabular}{|l|l|l|l|}
\hline $\begin{array}{l}\text { Apresentação } \\
\text { clínica }\end{array}$ & $\begin{array}{l}\text { RSA } \\
\text { grave }\end{array}$ & $\begin{array}{l}\text { RSA } \\
\text { curso agravado }\end{array}$ & $\begin{array}{l}\text { RSA } \\
\text { persistente }\end{array}$ \\
\hline $\begin{array}{l}\text { RSA não-complicada sem } \\
\text { doença associada }\end{array}$ & $A B$ & $A B$ & $\begin{array}{l}\text { AB ou observação } \\
\text { adicional durante 3 dias }\end{array}$ \\
\hline $\begin{array}{l}\text { RSA com complicações } \\
\text { orbitárias ou intracranianas }\end{array}$ & $A B$ & $A B$ \\
\hline $\begin{array}{l}\text { RSA com OMA, pneumonia, } \\
\text { adenite ou AASGA }\end{array}$ & $\mathrm{AB}$ & $\mathrm{AB}$ & $\mathrm{AB}$ \\
\hline
\end{tabular}

RSA - Rinosinusite bacteriana aguda; AB - antimicrobianos; OMA - otite média aguda; AASGA - amigdalite aguda a Streptococcus do grupo A.

Quadro 2. Tratamento da rinosinusite bacteriana aguda. Observação versus antimicrobianos. Adaptado de Wald ER, et al. Clinical Practice Guideline for the Diagnosis and Management of Acute Bacterial Sinusitis in Children Aged 1 to 18 Years. Pediatrics, 2013.

autores se existiu um tratamento nos 30 dias prévios com $\beta$-lactâmicos, se houver frequência de infantário, se tiver idade inferior a dois anos e se a doença for de grau moderado a grave). Em caso de alergia à penicilina (hipersensibilidade do tipo 1) preconiza-se a utilização de macrólidos; noutros tipos de hipersensibilidade recomenda-se a utilização de cefalosporinas de segunda e de terceira geração ou de clindamicina.

\subsubsection{Amigdalite Aguda}

É um processo inflamatório agudo das amígdalas palatinas, sendo que geralmente esta inflamação se estende às amígdalas faríngeas e linguais. Os termos faringite aguda, tonsilite aguda e AA são utilizados como equivalentes (figura 3).

A AA é, na grande maioria dos casos e em qualquer idade, virusal. Em crianças saudáveis, mais de 90\% das infeções agudas com envolvimento faríngeo são causadas por rinovírus, coronavírus, adenovírus, influenza $A$ e $B$, parainfluenza 1, 2 e 3, vírus Epstein-Barr, citomegalovírus, enterovírus, Streptococcus grupo A (SGA) e Mycoplasma pneumoniae.

As causas bacterianas de AA são muito menos frequentes e incluem sobretudo o SGA, outros Streptococcus (grupo C e G) e o Fusobacterium necrophorum, responsável pelo síndrome de Lemiérre.

O SGA é a etiologia mais frequente de AA bacteriana sendo responsável por 15 a 37\% da totalidade dos casos de AA. A infeção processa-se pelo contacto direto com secreções respiratórias de doente com AA a SGA (AASGA), sendo o período de incubação normalmente de dois a cinco dias. Vários estudos comprovam a existência de portadores assintomáticos de SGA na orofaringe, podendo a sua prevalência atingir os dez a 20\%. A AASGA ocorre entre os cinco e os 15 anos (inferior a dez por cento nos menores de três anos e insignificante nos menores de 18 meses), sendo típica do inverno ou do início da primavera e caracteriza-se por odinofagia de início súbito associada a febre alta, cefaleia, náuseas, vómitos e dor abdominal. Há inflamação faringo-amigdalina com hiperémia 

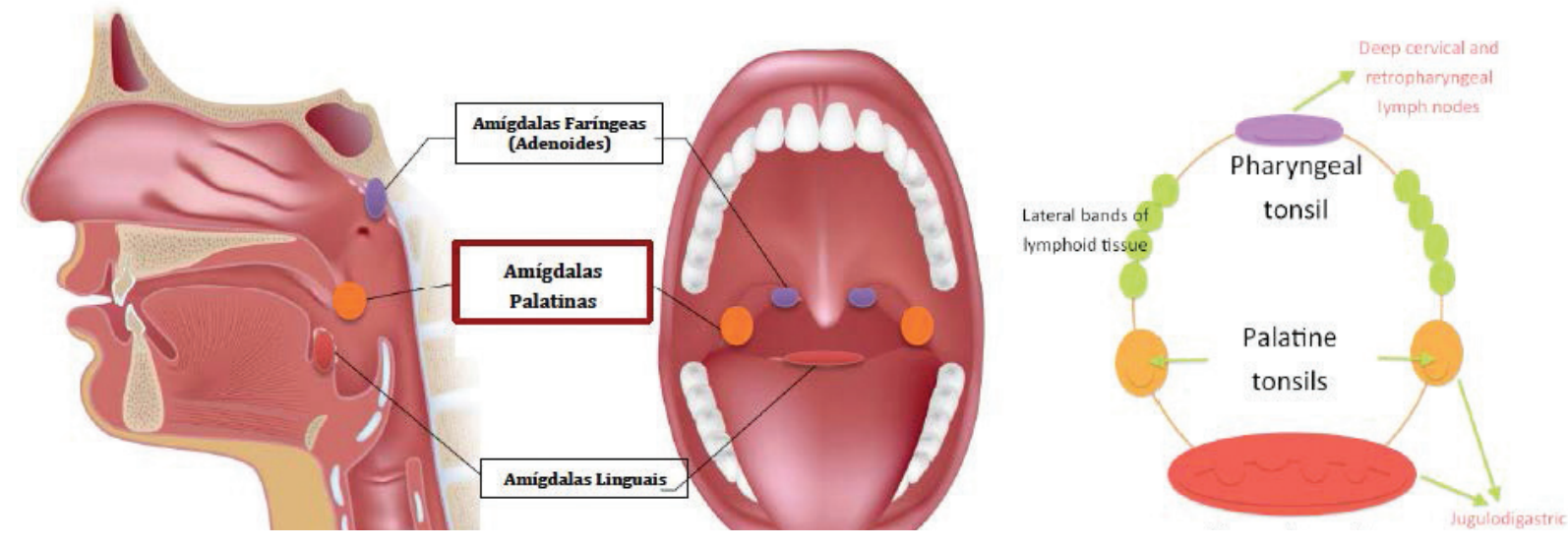

Figura 3. Grande anel linfático de Waldeyer-pirogof que consiste nos adenoides (localizados superiormente na NF), nas amígdalas palatinas (lateralmente na orofaringe) e nas amígdalas linguais (inferiormente na hipofaringe e recobertas pela mucosa no terço posterior da língua). Adaptado de Functional Anatomy of the Airway (http://clinicalgate.com/functional-anatomy-of-the-airway/).

intensa, existência de exsudado amigdalino, petéquias no palato (figura 4) e faringe posterior e por vezes uma adenite cervical anterior, muitas vezes dolorosa. Por vezes há exantema escarlatiniforme (exantema escarlate, rugoso e áspero ao toque, com tendência à confluência e que se distribui pelo pescoço e tronco, com acentuação das pregas axilares, antecubitais e inguinais e língua em morango).

Uma vez que a AASGA é provavelmente a única etiologia que beneficia de tratamento com $A B$ impõe-se pesquisa do SGA.

Infelizmente o diagnóstico de AASGA baseado unicamente em critérios clínicos é pouco confiável, uma vez que os sinais e sintomas são variáveis e a gravidade da doença vai desde a existência de odinofagia ligeira isolada a amigdalite exsudativa com febre alta, recusa alimentar e prostração. O diagnóstico complica-se ainda mais pelo facto da infeção por outros agentes, nomeadamente por alguns vírus, ser clinicamente indistinguível da AASGA, não existindo qualquer sinal

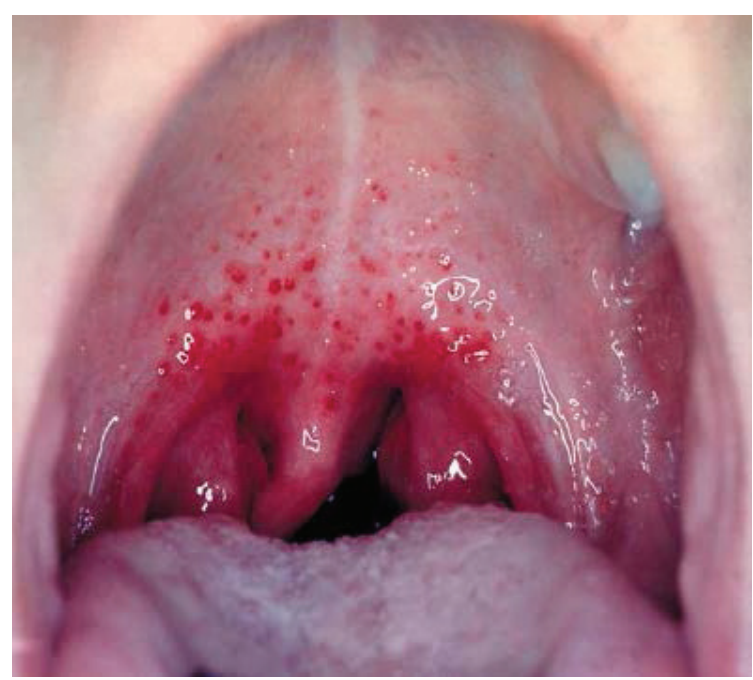

Figura 4. Amigdalite aguda a Streptococcus do grupo A. Fotografia do autor.

ou sintoma isolado que identifique eficazmente a AASGA. Foram assim desenvolvidos sistemas de pontuação clínicos na tentativa de predizer a probabilidade de infeção por SGA em crianças e adultos com AA. Estes sistemas baseiam-se na avaliação de dados clínicos sugestivos de 


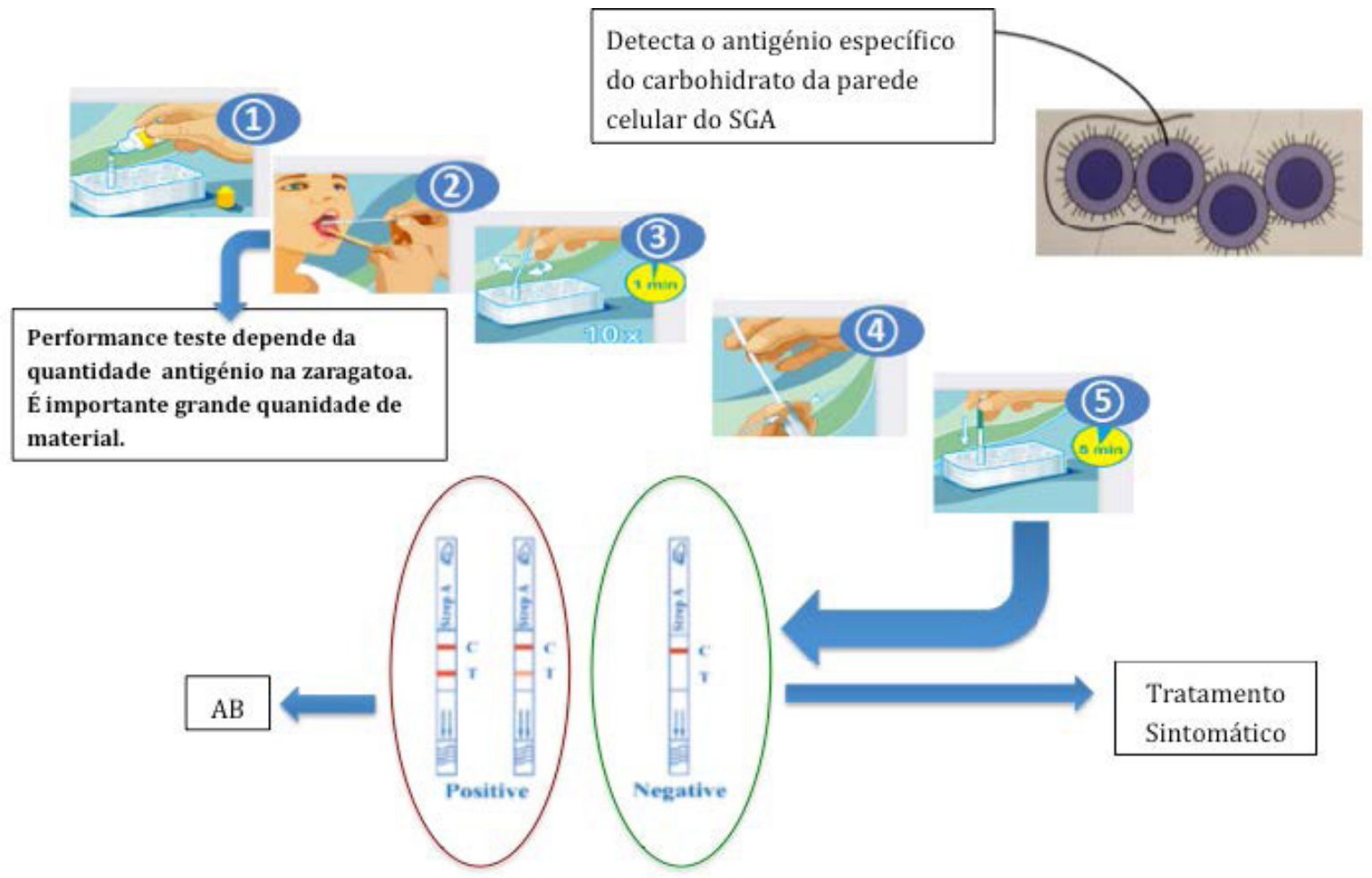

Figura 5. Realização e interpretação do teste diagnóstico antigénico rápido.

O TDAR baseia-se na deteção rápida e qualitativa do antigénio do SGA.

AASGA, vulgarmente conhecidos como critérios de CENTOR (como existência de febre, edema ou exsudato amigdalino, gânglios cervicais anteriores aumentados e dolorosos e ausência tosse), atribuindo a pontuação de um ponto por cada critério cumprido. O adicionar de outros critérios como a idade e a época do ano, pode ainda aumentar a probabilidade de diagnóstico, no entanto mesmo com scores de pontuação igual ou superior a quatro, a probabilidade de AASGA não ultrapassa os 60\%. O gold standard para o diagnóstico de AASGA foi durante muitos anos o isolamento de SGA na cultura da orofaringe em crianças e adultos com AA, e vários estudos confirmaram que a abordagem diagnóstica que preconiza a realização de exames microbiológicos nas crianças com epidemiologia e manifestações clínicas sugestivas de AASGA apresenta maior custo beneficio e menor taxa de prescrição de $A B s$, do que a abordagem diagnóstica baseada apenas na clínica e epidemiologia. O aparecimento e comercialização de testes sensíveis e específicos que permitem a deteção rápida do antigénio do SGA na orofaringe, o chamado teste diagnóstico antigénico rápido (TDAR), veio revolucionar o diagnóstico de AASGA e obviar a necessidade de realização de exames culturais (figura 5). O diagnóstico e tratamento da AA em idade pediátrica foram também, à semelhança da OMA, alvo de uma NOC da Direção-Geral da Saúde. 


\begin{tabular}{|c|c|c|c|c|c|}
\hline & Antibiótico & Via & Dose & $\mathrm{N}^{\circ}$ Tomas & Duração \\
\hline $1^{a}$ Linha & Amoxicilina & Oral & $\begin{array}{l}50 \text { mg/Kg/dia } \\
\text { (máx } 1 \mathrm{~g} / \mathrm{dia} \text { ) }\end{array}$ & $12 / 12 \mathrm{~h}$ & 10 dias \\
\hline $\begin{array}{l}\text { Alternativa } \\
1^{\mathrm{a}} \text { Linha }\end{array}$ & $\begin{array}{l}\text { Penicilina G } \\
\text { benzatínica }\end{array}$ & I.M. & $\begin{array}{l}<27 \mathrm{Kg}=600.00 \mathrm{U} \\
\geq 27 \mathrm{Kg}=1.200 .000 \mathrm{U}\end{array}$ & Dose única & Dose única \\
\hline \multirow{4}{*}{$\begin{array}{l}\text { Alergia à penicilina } \\
\text { Hipersensibilidade } \\
\text { tipo } 1\end{array}$} & Claritromicina & Oral & $\begin{array}{l}15 \text { mg/Kg/dia } \\
\text { (máx 1g/dia) }\end{array}$ & $12 / 12 \mathrm{~h}$ & 10 dias \\
\hline & Eritromicina & Oral & $\begin{array}{l}50 \text { mg/Kg/dia } \\
\text { (máx 2g/dia) }\end{array}$ & $\begin{array}{l}6 / 6 h \text { ou } \\
8 / 8 h\end{array}$ & 10 dias \\
\hline & Azitromicina & Oral & $\begin{array}{l}12 \text { mg/Kg/dia } \\
\text { (máx } 500 \text { mg/dia) }\end{array}$ & $24 / 24 h$ & 5 dias \\
\hline & Clindamicina & Oral & $\begin{array}{l}20 \text { mg/Kg/dia } \\
\text { (máx } 1.8 \mathrm{~g} / \mathrm{dia} \text { ) }\end{array}$ & $8 / 8 \mathrm{~h}$ & 10 dias \\
\hline \multirow{3}{*}{$\begin{array}{l}\text { Alergia à penicilina } \\
\text { Hipersensibilidade } \\
\text { não tipo } 1\end{array}$} & Cefadroxil & Oral & $\begin{array}{l}30 \text { mg/Kg/dia } \\
\text { (máx 1g/dia }\end{array}$ & $24 / 24 h$ & 10 dias \\
\hline & Cefeprozil & Oral & $\begin{array}{l}30 \text { mg/Kg/dia } \\
\text { (máx 2g/dia) }\end{array}$ & $12 / 12 \mathrm{~h}$ & 10 dias \\
\hline & Cefuroxime-axetil & Oral & $\begin{array}{l}\text { 20-30 mg/kg/dia } \\
\text { (máx 1g/dia) }\end{array}$ & $12 / 12 \mathrm{~h}$ & 10 dias \\
\hline
\end{tabular}

Quadro 3. Antimicrobianos utilizados no tratamento da amigdalite aguda a Streptococcus do grupo A AASGA. Diagnóstico e Tratamento da Amigdalite Aguda na Idade Pediátrica. Norma da Direção- Geral da Saúde, 2012.

De acordo com a NOC de AA (figura 6), perante uma criança com idade igual ou superior a três anos com AA e epidemiologia e clínica sugestivas da etiologia SGA, deverá ser realizado TDAR e prescrito $A B$ no caso de este ser positivo. No entanto, se a epidemiologia e a clínica forem sugestivas de etiologia viral (rinorreia, tosse, rouquidão, úlceras orais ou diarreia), deverá ser assumido AA vírica e não deverá ser realizado TDAR. A cultura da orofaringe reserva-se assim às crianças e adolescentes com epidemiologia e manifestações clínicas sugestivas de AASGA e presença de uma ou mais das seguintes situações: TDAR não disponível; TDAR negativo e contacto com infeção confirmada por SGA; TDAR negativo e antecedentes pessoais ou familiares de febre reumática aguda, ou glomerulonefrite pós-estreptocócica ou choque tóxico estreptocócico e no doente com hipersensibilidade tipo 1 aos $\beta$-lactâmicos de forma a permitir a realização do antibiograma.

Perante uma AASGA confirmada o $A B$ de primeira linha é a amoxicilina $(50 \mathrm{mg} / \mathrm{Kg} / \mathrm{dia}$, de 12 em 12 horas, por via oral, durante dez dias) devido à sua eficácia (o SGA é universalmente sensível à penicilina), espetro estreito, perfil de segurança, bom paladar e baixo custo. Se não for possível a administração de AB por via oral, ou não é expectável que a criança cumpra a totalidade do tratamento, a penicilina $\mathrm{G}$ benzatínica (600.000 U, se peso inferior a $27 \mathrm{~kg}$ e 1.200 .000 


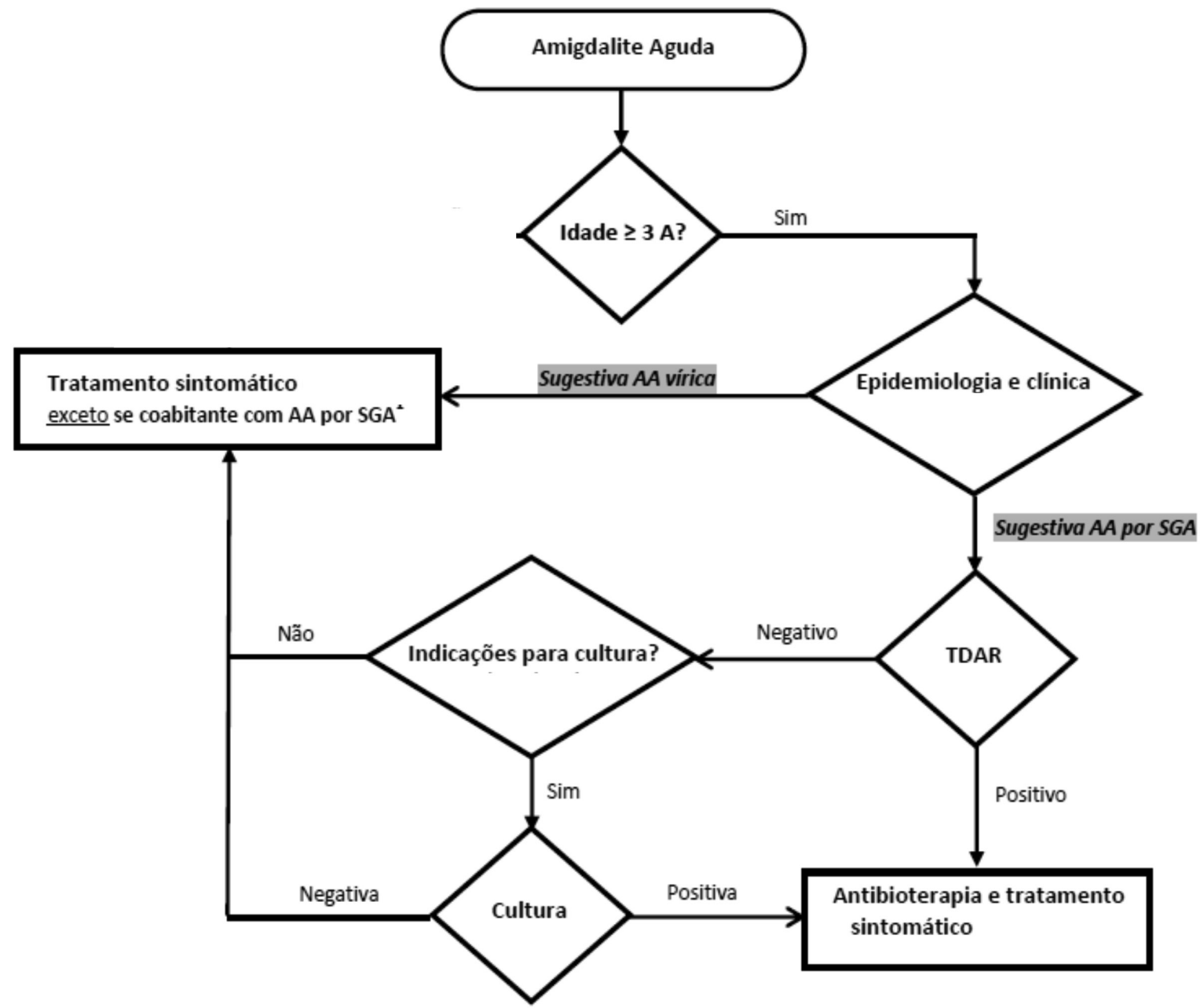

Figura 6. Algoritmo de atuação na amigdalite aguda. Adaptado de Diagnóstico e Tratamento da Amigdalite Aguda na Idade Pediátrica. Norma da Direção Geral da Saúde, 2012.AA - amigdalite aguda; SGA - Streptococcus do grupo A; TDAR - teste diagnóstico antigénico rápido.

U se peso superior ou igual a $27 \mathrm{Kg}$, intramuscular, dose única) é o $A B$ de escolha, apesar da sua administração ser dolorosa. A utilização de cefalosporinas de primeira geração (cefadroxil) ou de segunda geração (cefuroxime-axetil e cefeprozil) deve ser reservado para casos com hipersensibilidade à penicilina não tipo 1, uma vez que têm espetro mais alargado, potencial de indução de resistências e custo tendencialmente superior. Na hipersensibilidade à penicilina tipo 1 , os $A B s$ de escolha são os macrólidos ou a clindamicina (quadro 3).

\subsubsection{Infeções da laringe e da traqueia}

A inflamação da mucosa e o edema causados pelas infeções da laringe e da traqueia podem causar obstruções da via aérea (VA) 
ameaçadoras da vida nas crianças, sobretudo nas pequenas.

A gravidade da obstrução da VA superior é avaliada pelo grau de retração supraesternal e subcostal, pela frequência respiratória, pela frequência cardíaca, pelo grau de agitação, pela presença de sinais como cansaço e exaustão devido ao esforço respiratório e pela existência de cianose central que é indicativa de hipoxémia grave e da necessidade de intervenção emergente. A monitorização da saturação periférica de oxigénio é o melhor método de medição da hipoxémia.

Antes do século XX todas as doenças "croup-like" eram assumidas como difteria. Atualmente o termo "croup" é usado para designar um número de doenças respiratórias (quadro 4) que se caracteriza pela existência de estridor (som monofônico ouvido predominantemente na inspiração) de grau variável, tosse estridulosa (descrita como "tosse de cão"), rouquidão (devido à inflamação da laringe) e grau variável de dispneia.

A quase totalidade dos casos de croup são, de facto, laringotraqueítes agudas (LTA) ou croups espasmódicos, e afetam tipicamente crianças abaixo dos seis anos de idade com um pico de incidência entre os sete e os 36 meses.

O tratamento da LTA e do croup espasmódico consiste na utilização de corticoides e de adrenalina nebulizada. O tratamento com corticoides é atualmente recomendado e várias meta-análises de ensaios randomizados têm consistentemente demonstrado uma melhoria significativa sintomática das crianças tratadas com estes. Os regimes mais bem estudados são os que utilizam a dexametasona por via oral $(0,6 \mathrm{mg} / \mathrm{Kg})$ em dose única ou budenosido nebulizado (2 mg). A adrenalina nebulizada (diluição 1:1000) tem sido igualmente estudada de forma extensa no tratamento da LTA e na presença de dificuldade respiratória moderada a grave comprovou-se que tratamentos repetidos com adrenalina nebulizada resultam numa diminuição da necessidade de entubação. Se houver suspeita ou confirmação de sobreinfecção bacteriana dever-se-á utilizar ABs com atividade contra Staphylococcus aureus, SGA, Streptococcus pneumoniae, Haemophilus Influenza e Moraxella catarrhalis.

\subsubsection{Epiglotite aguda}

A epiglotite define-se como uma inflamação da epiglote e das estruturas supraglóticas adjacentes. O edema supraglótico reduz o calibre da via aérea superior, causando um reduzido fluxo de ar turbulento durante a inspiração e resultando num som característico designado por estridor. A obstrução da via aérea, que pode causar uma paragem cardio-respiratória, pode ser rapidamente progressiva e os sinais de obstrução grave da via aérea superior poderão estar ausentes até às fases finais da doença, altura em que a obstrução da via aérea é quase total.

Em crianças previamente saudáveis a etiologia da epiglotite é de origem bacteriana. A causa mais frequente é o Haemophilus influenzae tipo b (Hib) apesar da diminuição drástica do número de casos após introdução da vacina conjugada contra esta bactéria. Outras bactérias que podem também causar epiglotite são outros Haemophilus influenza (tipos A, F e não-tipáveis), o Streptococcus pneumoniae e o Staphylococcus aureus.

A epidemiologia da epiglotite alterou-se radicalmente após a introdução da vacina contra o $\mathrm{Hib}$, sendo as principais modificações a diminuição 


\begin{tabular}{|c|c|c|c|c|}
\hline $\begin{array}{l}\text { Definição e } \\
\text { características }\end{array}$ & $\begin{array}{l}\text { Croup } \\
\text { espasmódico }\end{array}$ & $\begin{array}{l}\text { Laringotraqueíte } \\
\text { aguda }\end{array}$ & $\begin{array}{l}\text { Laringotraqueobronquite } \\
\text { e Traqueíte bacteriana }\end{array}$ & Difteria laríngea \\
\hline Definição & $\begin{array}{l}\text { Início súbito } \\
\text { nocturno } \\
\text { de estridor } \\
\text { associado a } \\
\text { coriza. Sem } \\
\text { inflamação }\end{array}$ & $\begin{array}{l}\text { Inflamação da } \\
\text { laringe e da traqueia }\end{array}$ & $\begin{array}{l}\text { Inflamação da laringe, da } \\
\text { traqueia, dos brônquios ou } \\
\text { pulmão. Início similar à LTA } \\
\text { mas doença mais grave }\end{array}$ & $\begin{array}{l}\text { Infecção } \\
\text { causada pelo } \\
\text { Corynebacterium } \\
\text { diphtheriae, } \\
\text { envolvendo a } \\
\text { laringe e que resulta } \\
\text { numa obstrução } \\
\text { progressiva da VA }\end{array}$ \\
\hline Idade típica & $3 \mathrm{M}$ a $3 \mathrm{~A}$ & $3 \mathrm{M}$ a $3 \mathrm{~A}$ & $3 \mathrm{M}$ a $3 \mathrm{~A}$ & Todas as idades \\
\hline $\begin{array}{l}\text { Antecedentes } \\
\text { pessoais e } \\
\text { familiares }\end{array}$ & $\begin{array}{l}\text { História familiar } \\
\text { possível; ataque } \\
\text { prévio possível }\end{array}$ & $\begin{array}{l}\text { História familiar } \\
\text { possível }\end{array}$ & História familiar possível & $\begin{array}{l}\text { Ausência de } \\
\text { vacinação }\end{array}$ \\
\hline Pródromo & Coriza mínima & Coriza & Coriza & Faringite \\
\hline Início & $\begin{array}{l}\text { Súbito. Sempre } \\
\text { à noite. Criança } \\
\text { deita-se bem } \\
\text { e acorda } \\
\text { subitamente } \\
\text { com tosse } \\
\text { e estridor }\end{array}$ & $\begin{array}{l}\text { Rápido, } \\
\text { mimetizando uma } \\
\text { NFA. Febre nas } \\
\text { primeiras } 24 \mathrm{H} \\
\text { e passadas } 12 \text { a } \\
48 \mathrm{H} \text { surgem sinais } \\
\text { de obstrução da } \\
\text { VA superior }\end{array}$ & $\begin{array}{l}\text { Gradualmente progressivo } \\
\text { num período de } 12 \mathrm{H} \text { a } 7 \mathrm{D}\end{array}$ & $\begin{array}{l}\text { Lento mas } \\
\text { progressivo num } \\
\text { período de } 2 \text { a 3D }\end{array}$ \\
\hline $\begin{array}{l}\text { Sinais e } \\
\text { sintomas }\end{array}$ & $\begin{array}{l}\text { Rouquidão, } \\
\text { tosse } \\
\text { estridulosa, } \\
\text { estridor ligeiro } \\
\text { a moderado, } \\
\text { ausência } \\
\text { de febre }\end{array}$ & $\begin{array}{l}\text { Rouquidão, tosse } \\
\text { estridulosa, estridor } \\
\text { ligeiro a moderado, } \\
\text { febre }\left(38-40^{\circ} \mathrm{C}\right)\end{array}$ & $\begin{array}{l}\text { Rouquidão, tosse } \\
\text { estridulosa, estridor } \\
\text { grave, febre }\left(38-40^{\circ} \mathrm{C}\right) \text {, } \\
\text { aparência tóxica }\end{array}$ & $\begin{array}{l}\text { Rouquidão, tosse } \\
\text { estridulosa, } \\
\text { disfagia e faringite } \\
\text { membranosa, } \\
\text { estridor ligeiro } \\
\text { a grave, febre } \\
\left(38,5^{\circ} \mathrm{C}\right) \text {, aparência } \\
\text { não tóxica }\end{array}$ \\
\hline Microbiologia & Igual à LTA & $\begin{array}{l}\text { Parainfluenza } \\
\text { e Influenza. } \\
\text { VSR, Sarampo } \\
\text { e Adenovírus }\end{array}$ & $\begin{array}{l}\text { Sobreinfecção bacteriana } \\
\text { por Staphylococcus } \\
\text { aureus. Outros } \\
\text { agentes incluem SGA, } \\
\text { Streptococcus pneumoniae, } \\
\text { Haemophilus Influenza } \\
\text { e Moraxella catarrhalis }\end{array}$ & $\begin{array}{l}\text { Corynebacterium } \\
\text { diphtheriae }\end{array}$ \\
\hline
\end{tabular}

LTA - laringotraqueíte aguda; H - horas; D - dias; M - meses; A - anos; VA- via aérea; SGA - Streptococcus do grupo A; VSR - vírus sincicial respiratório; ${ }^{\circ} \mathrm{C}$ - graus Celsius.

Quadro 4. Classificação, definição e características clínicas das doenças "croup-like". Adaptado de Cherry JD. Clinical practice. Croup. New England Journal of Medicine, 2008. 
drástica da incidência e a idade média do diagnóstico ter passado para mais tarde, dos três para os seis a doze anos.

\section{A suspeita de epiglotite constitui uma} emergência médica, sendo essencial o reconhecimento e o tratamento imediato. As características clínicas dependem da idade e da gravidade, sendo que a criança se apresenta classicamente com dificuldade respiratória e estridor, assumindo uma posição característica de sentada e imóvel, recusando muitas vezes o toque ou a posição de decúbito, com inclinação anterior do tronco, hiperextensão do pescoço e elevação do mento, numa tentativa de maximizar o diâmetro de uma via aérea obstruída. A sialorreia está muitas vezes presente e a tosse está tipicamente ausente. É característico o início súbito de febre alta, superior a $39^{\circ} \mathrm{C}$, odinofagia e disfagia graves, voz abafada e aparência tóxica.

A tentativa de visualização da epiglote com o auxílio de espátula, bem como a realização de radiografias laterais do pescoço não devem ser efectuadas, uma vez que poderão precipitar obstrução total da via aérea e paragem cárdio-respiratória, sendo a atitude fundamental o controlo da via aérea com entubação programada, recorrendo, se necessário, a intensivistas e a anestesistas pediátricos com experiência em permeabilizar via aérea (VA) difícil. A visualização de uma epiglote edemaciada e eritematosa durante a entubação confirma o diagnóstico. Exames complementares, nomeadamente hemograma, marcadores de infeção sistémicos, cultura do exsudato da epiglote e hemocultura só deverão ser efetuados após estabilidade clínica e controlo da VA. O diagnóstico diferencial de epiglotite

\begin{tabular}{|l|l|l|}
\hline & LTA & Epiglotite \\
\hline Início & Dias & Horas \\
\hline Coriza & Sim & Não \\
\hline Tosse & Sim, estridulosa & Não, ligeira \\
\hline $\begin{array}{l}\text { Ingestão } \\
\text { de líquidos }\end{array}$ & Sim & Não \\
\hline Sialorreia & Não & Sim \\
\hline Aparência & Boa ou mediana & Tóxica $^{\circ}$ \\
\hline Febre & $<39^{\circ} \mathrm{C}$ & $>39^{\circ} \mathrm{C}$ \\
\hline Estridor & Sim & Sim \\
\hline $\begin{array}{l}\text { Voz e } \\
\text { choro }\end{array}$ & Rouquidão & $\begin{array}{l}\text { Abafada, } \\
\text { relutância } \\
\text { em falar }\end{array}$ \\
\hline
\end{tabular}

LTA - laringotraqueíte aguda; ${ }^{\circ} \mathrm{C}$ - graus Celsius

Quadro 5. Características clínicas da Laringotraqueíte aguda e Epiglotite. Adaptado de Lissauer T, et al. Illustrated Textbook of Paediatrics. 4th Edition, 2011.

inclui outras causas de obstrução aguda da VA superior, nomeadamente LTA (quadro 5), traqueíte bacteriana, abcesso periamigdalino e retrofaríngeo, angioedema e difteria.

O tratamento da epiglotite consiste, como já referido, no controlo emergente da via aérea e da sua patência, seguido da administração de ABs apropriados à etiologia, nomeadamente de uma combinação de uma cefalosporina de terceira geração (ceftriaxone ou cefotaxime) com uma penicilina antiestafilocócica (flucloxacilina).

\subsection{FACTOS A RETER}

A prescrição racional de ABs é atualmente um dos grandes desafios da medicina.

Globalmente, e especificamente em Portugal, assiste-se a uma excessiva prescrição de $A B s$ em 
situações que não o justificam e por outro lado a uma prescrição exagerada de $A B s$ de largo espetro. As IVRS são responsáveis pela maioria da prescrição de $A B s$ apesar de serem causadas maioritariamente por vírus.

Torna-se assim necessário seguir normas e abordagens racionais para o diagnóstico e tratamento das IVRS, bem como usar critérios clínicos validados para o diagnóstico de OMA, RSA e AASGA, situações que podem beneficiar da utilização de $A B s$.

A NFA é uma infeção viral que não necessita de prescrição de $A B s$. Na OMA, pode ser realizado um período de observação apenas com controlo da dor e sem prescrição imediata de $A B s$, em crianças com idade igual ou superior a seis meses.

O diagnóstico de RSA exige uma persistência dos sintomas respiratórios, sem melhorias, por um período superior a dez dias.

A AA é de origem virusal na maioria dos casos e na suspeita de AASGA deve ser, sempre que possível, realizado o TADR para confirmação desta etiologia.

Nas IVRS, se a decisão for a prescrição de ABs, a amoxicilina deverá ser o $A B$ de escolha.

Um quadro de obstrução respiratória alta, deve ser sempre avaliado e orientado com especial cuidado e senso clínico.

\section{Leitura complementar}

Diagnóstico e Tratamento da Amigdalite Aguda na Idade Pediátrica. Norma da Direção- Geral da Saúde, 2012. (https://www.dgs.pt/directrizes-da-dgs.aspx).

Diagnóstico e Tratamento da Otite Média Aguda na Idade Pediátrica. Norma da Direção- Geral da Saúde, 2012. (https://www.dgs.pt/directrizes-da-dgs.aspx

3) European Centre for Disease Prevention and Control. Surveillance of antimicrobial consumption in Europe, 2010. Stockholm: ECDC; 2013. (http://ecdc.europa.eu/ en/publications/Publications/antimicrobial-antibiotic-consumption-ESAC-report-2010-data.pdf).

Bisno AL. Acute pharyngitis. N Engl J Med, 2001.

Ellen R. Wald, et al. Clinical Practice Guideline for the Diagnosis and Management of Acute Bacterial Sinusitis in Children Aged 1 to 18 Years. Pediatrics, 2013.

Chow AW, et al. IDSA Clinical Practice Guideline for Acute Bacterial Rhinosinusitis in Children and Adults. Clin Infect Dis, 2012.

Cherry JD. Croup. N Engl J Med, 2008. 